\title{
IDENTIDADE EM LINGUÍSTICA APLICADA: EM DIREÇÃO A UMA SISTEMATIZAÇÃO CONCEITUAL
}

\author{
IDENTITY IN APPLIED LINGUISTICS: IDENTIDAD EN LINGÜÍSTICA APLICADA: \\ TOWARDS A SYSTEMATIZATION HACIA UNA SISTEMATIZACIÓN \\ OF THE CONCEPT CONCEPTUAL
}

\author{
Hélvio Frank* \\ Universidade Estadual de Goiás, Itapuranga, GO, Brasil \\ Mariney Pereira Conceição** \\ Universidade de Brasília, Instituto de Letras, \\ Departamento de Línguas Estrangeiras e Tradução, Brasília, DF, Brasil
}

\begin{abstract}
Resumo: A identidade é atualmente um tema linguístico e social bastante profícuo e abrange grandes discussões em Linguística Aplicada (REIS et al., 2011). Pesquisas desenvolvidas sob diferentes orientações teórico-metodológicas enxergam o conceito e suas caracterizações de maneira diversificada. Por se tratar de um fenômeno instalado no circuito da cultura, a gama de definições e exemplos produzidos por variadas frentes de estudo acaba por gerar sua robusta configuração. Esse alargamento parece relevante para acenar uma possível sistematização com vistas à análise científica do construto no universo das relações sociais mediadas por linguagem. Sob tais perspectivas, este artigo busca sistematizar percursos teóricometodológicos do conceito difundidos em estudos de Linguística Aplicada. Serve-se, para tanto, da condição interdisciplinar do campo de investigação científica, a fim de traçar algumas características da/s identidade/s e, em seguida, discutir abordagens utilizadas em pesquisas da área de Linguística Aplicada, incluindo propostas de taxonomia para análises futuras.
\end{abstract}

Palavras-chave: Linguística Aplicada. Identidade. Sistematização conceitual.

\begin{abstract}
Identity is currently a very important linguistic and social theme that comprehends relevant discussions in Applied Linguistics (REIS et al., 2011). Researches developed under different theoreticalmethodological orientations present the concept and its characterizations in distinct ways. Since it is a phenomenon instated in culture, the range of definitions and examples produced by various studies increases the identity's configuration. All this concept expansion seems significant to indicate a possible systematization to analyse, scientifically, the construct in the universe of language-mediated social relations. From these perspectives, this paper aims to systematize theoretical-methodological paths of the concept disseminated in Applied Linguistics studies. For this purpose, it uses the interdisciplinary aspects of the scientific research field, in order to present some characteristics of the identity and then discuss some approaches used in Applied Linguistics research, including taxonomic proposals for future analyses.
\end{abstract}

Keywords: Applied Linguistics. Identity. Conceptual systematization.

* Doutor em Linguística. Docente da Universidade Estadual de Goiás, Unidade Universitária de Itapuranga. ORCID: https://orcid.org/0000-0002-0553-8075. E-mail: helviofrank@hotmail.com.

** Doutora em Linguística Aplicada. Docente da Universidade de Brasília: ORCID: https://orcid.org/00000003-0989-0137. E-mail: marineydf@gmail.com. 
Resumen: Identidad es, actualmente, un tema lingüístico y social bastante proficuo, e incluye grandes discusiones en Lingüística Aplicada (REIS et al., 2011). Investigaciones desarrolladas bajo diferentes orientaciones teórico-metodológicas ven el concepto y sus caracterizaciones de manera diversificada. Por tratarse de un fenómeno instalado en el circuito de la cultura, a gama de definiciones y ejemplos producidos por variadas frentes de estudio generan su robusta configuración. Ese alargamiento parece relevante para saludar una posible sistematización con el objetivo de analizar científicamente el constructo en el universo de las relaciones sociales mediadas por lenguaje. Bajo tales perspectivas, este artículo busca sistematizar recorridos teórico-metodológicos del concepto difundidos en estudios de lingüística Aplicada. Para ello, se sirve de la condición interdisciplinaria del campo de investigación científica, para trazar algunas características de la/s identidad/es, y a continuación, discutir abordajes utilizadas en investigaciones del área de lingüística Aplicada, incluyendo propuestas de taxonomía para analices futuras.

Palabras clave: Lingüística Aplicada. Identidad. Sistematización conceptual.

\section{INTRODUÇÃO}

A busca por um 'sentido de si' (HALL, 2006) ou por uma compreensão de quem somos que nos possa garantir um lugar no mundo ou nos forneça um senso de pertencimento social é um assunto que vem despertando amplo interesse nos estudos de linguagem (BARCELOS, 2013; REIS et al., 2011; MAIOR; LUZ, 2019; MACHADO; GIL, 2017; MOITA LOPES; BASTOS, 2011). Amparadas pelas Ciências Humanas e Sociais (CIAMPA, 1987, 2002; LEMKE, 2008; MOSCOVICI, 2013) e pelos Estudos Culturais (HALL, 2003, 2006, 2009; SILVA, 2009; WOODWARD, 2009), pesquisas sobre identidade $^{1}$ em LA se sustentam pelo caráter social e relacional humano e apresentam desde uma compreensão sólida, coerente e estável enquanto fenômeno, atravessado por heranças genéticas e culturais, a uma inteligibilidade mais instável, contraditória e dinâmica.

À medida que o tempo passa e a vida em sociedade se transforma, outros contextos e relações sociais nos oferecem possibilidades para pensar a identidade. Entretanto, qualquer tentativa de sistematização de um conceito tão complexo, colocando à prova proposições teóricas avolumadas acerca do tema, parece-nos uma empreitada bastante ambiciosa. Cientes da complexidade que envolve a tarefa, neste artigo buscamos sistematizar percursos teórico-metodológicos do conceito identidade difundidos nos estudos de Linguística Aplicada no Brasil, caracterizando sua abordagem e propondo uma taxonomia para análise.

A partir de consultas a estudos no campo da linguagem (BARCELOS, 2013; REIS et al., 2011), da participação em grupos de pesquisa e de nosso trabalho com o tema (CÂNDIDO JÚNIOR et al., 2020; CAPPARELLI et al., 2018; CONCEIÇÃO, 2013, 2020; CONCEIÇÃO; ANDRADE, 2020; CONCEIÇÃO; FLORINDO, 2020; CONCEIÇÃO et al., 2019; 2020; CUNHA; OLIVEIRA, 2019; MACHADO et al., 2016; OLIVEIRA, 2017a, 2017b, 2018; UTIM; FRANK, 2020), nas próximas seções perscrutamos características e conceitos de identidade, para, em seguida, discorrermos sobre as abordagens mobilizadas acerca do construto em pesquisas de LA, incluindo propostas de taxonomias teórico-metodológicas para análises futuras.

\footnotetext{
${ }^{1}$ Compreendemos o termo identidade, independentemente de seu uso no singular ou plural, como um processo linguístico multifacetado de identificação ou diferenciação de uma pessoa, coisa, grupo etc.
} 


\section{COMPLEXIDADES E PERSPECTIVAS DO CONCEITO DE IDENTIDADE EM LA}

Identidade não é uma categoria teórica elaborada recentemente na LA. Em muitos desses trabalhos, nem sempre há menção explícita ao termo, muito embora ele apareça como uma espécie de produto/resultado de discursos, isto é, um pano de fundo alimentado por outros fenômenos sociais focalizados, de modo a refletir a identidade.

No contexto de ensino/aprendizagem de línguas, sua problemática, segundo Deters (2011), inaugura-se com a mudança de perspectiva nos estudos de aquisição de linguagem, os quais passaram a concentrar foco no aprendiz em contato com a cultura/língua diferente e a conceber a língua em uso. A partir dessa guinada sociocultural, ocorrida na década de 1970, passaram a predominar os domínios social e contextual das relações constitutivas do ser - que é igualmente social, heterogêneo e complexo (DETERS, 2011) - como modelo de orientação para o trabalho com a identidade e fenômenos associados (FIRTH; WAGNER, 2007).

Considerando o contexto de diferentes movimentos migratórios, de imersão (DETERS, 2011) e de contato ao redor do mundo, no ensino de línguas o modo como os envolvidos veem a si próprios e ao/s outro/s em meio às relações sociais estabelecidas (DE NARDI; GIL, 2015), fundindo diferenças étnicas, raciais, culturais etc., perpassa o domínio de compreensão da identidade (NORTON; MCKINNEY, 2011). Segundo Firth e Wagner (2007), a dimensão existencial do aprendiz, vigorada pelos questionamentos de quem sou, onde estou e para onde vou evoca consciência identitária. Entretanto, esse entendimento muitas vezes escapa a uma sistematização conceitual devido à volumosa configuração do construto.

O caráter difuso da identidade se reserva às suas múltiplas facetas caracterizadoras, às abundantes bases e afiliações teóricas perseguidas, com configurações que variam conforme a maneira como é explorada no contexto de pesquisa, bem como à sua correlação com outros componentes e objetos. Essa complexidade prejudica, em certa proporção, seu rastreamento (DETERS, 2011). Por isso, em nossa trajetória de estudos (CÂNDIDO JÚNIOR et al., 2020; CONCEIÇÃO, 2013, 2020; OLIVEIRA, 2017a, 2017 b 2018 ) temos reafirmado que identidade constitui fenomenologia em objeto e, pela dimensão sociocultural que ocupa, precisa ser esquadrinhada qualitativa, interpretativa e contextualmente (VARGHESE et al., 2005).

É consenso, na área, que o componente social é uma condição precípua à propagação da identidade (FIRTH; WAGNER, 2007; KLEIMAN, 1998; LASKY, 2005; LIBERALI, 2004). Vários fenômenos, como interação, socialização, práticas sociais, cultura, comunicação, entre outros, cujo caráter social imbrica-se à linguagem no processo, acionam (in)diretamente a identidade. Crenças, valores, motivações, aparência, escolhas, costumes etc. também operam nessa ordem (BARCELOS, 2013, 2015). Assim, a simbiose de elementos a ser examinada é inevitável quando se pressupõe a existência de uma pessoa em conjunto com outra/s, atribuindo sentidos na vida social mediada pela linguagem.

A identidade geralmente é resenhada para se descobrir a respeito de sua trama nas relações sociais. Comumente aparece associada a outros fenômenos, os quais, a nosso 
ver, precisariam ser tratados de maneira estanque em acepção, para que a inevitável imbricação não sirva apenas para incluí-la, como se fizesse parte de um mesmo conceito, devido a suas características se diluírem ou se assemelharem em algum momento no processo. Instala-se, portanto, uma dificuldade de mapeamento inerente às complexidades da própria configuração conceitual, oriunda do limite de conexão da identidade com outros elementos. Talvez aí esteja o grande desafio dos linguistas aplicados: desgrudar as extensões e ramificações que anunciam a identidade geralmente associada a outros conceitos que também se orientam pelo fenômeno da linguagem.

O exame da identidade também se alastra por intermédio de narrativas (BARCARO, 2012; CAPPARELLI et al., 2018; MISHLER, 2002; SILVA et al., 2007; TELLES, 2004; UTIM; FRANK, 2020), de interações, de significados dessas relações e de valores surtidos em atos comunicativos. Com isso, o teor de manifestação de sentidos circunstanciado por práticas intersubjetivas, incluindo ordens linguísticas de negociação, construção, classificação, avaliação etc., mostra-se bastante produtivo para o fluxo e, consequentemente, para a interpretação da identidade (BUCHOLTZ; HALL, 2005; PAVLENKO; BLACKLEDGE, 2004). É na trama social instalada por interlocutores e enredada por elementos semióticos (BLOMMAERT, 2005) que linguagem e identidade se amalgamam, dificultando, assim, a dissociação dos elementos (OLIVEIRA, 2017b, 2018).

O artefato simbólico presente na linguagem garante ao indivíduo a oportunidade de construir o mundo e suas relações sociais, e é nessa conjuntura que se forma a identidade. Talvez seja essa uma das prerrogativas para a LA se enveredar na pesquisa sobre o tema, já que é pelo atributo da comunicação entre pessoas que a identidade se articula. Afinal, perscruta-se a identidade a partir da ação de linguagem que pessoas em comunicação socialmente realizam. Logo, é buscado, como interpretação, o registro histórico de amparo desse consenso coletivizado no ato linguístico, mesmo que, em muitos casos, não deixe de haver estereótipos, segregações e classificações enrijecidas (LEMKE, 2008).

Em geral, as práticas sociais, quando ponderadas sob linguagem, são responsáveis por instaurar o fluxo da identidade, o qual, de acordo com Norton (2016, p. 476), se relaciona à maneira de ver a vida e à "forma como uma pessoa compreende sua relação com o mundo, como essa relação é estruturada no tempo e espaço e como essa pessoa compreende possibilidades futuras" ${ }^{2}$. Com efeito, linguistas aplicados recorrem a esse entendimento acerca da identidade para implementar suas investigações.

\section{ABORDAGENS PARA O ESTUDO DO CONCEITO DE IDENTIDADE EM LA}

A existência social do ser humano integrada à relação ontológica implica a emergência da identidade, a qual se abastece dessa orientação justamente por pressupor, em sua dinâmica, a relação eu-outro/s. Desse modo, surge e se sustenta a partir dos

\footnotetext{
2 Do original: "the way a person understands his or her relationship to the world, how that relationship is constructed across time and space, and how the person understands possibilities for the future (NORTON, 2016, p. 476).
} 
caráteres relacional e contrastivo, mediada pela linguagem, apropriada e ajustada conforme o contexto. Embalado por toda essa complexidade, o tema, que também é bastante explorado em seu envolvimento com segunda língua (PAVLENKO; NORTON, 2007), numa perspectiva móvel de celebração (CORACINI, 2007), mostra-se prolixo, interdisciplinar e, com isso, multiplica eixos de análise, especialmente quando integrado a outros objetos e processos pesquisados.

Em sua tese, Falasca (2017) propõe quatro perspectivas sociais de estudo para a identidade: 1) pós-estrutural, 2) aprendizagem socialmente situada: socialização e comunidades de prática, 3) sociocultural e, por fim, 4) bakhtiniana, esforço no qual se concentra para relacionar aspectos da identidade e aprendizagem da língua estrangeira (alemão). Entretanto, revisitando estudos que lidam com o fenômeno, sem descartar a caracterização proposta pela autora, mas compreendendo-a sob um novo arranjo, apostamos na plausibilidade de três abordagens predominantes em LA, sobre as quais passamos a discorrer:

\subsection{ABORDAGEM DISCURSIVA}

Pautada na dimensão pós-estruturalista, que tem Lacan, Derrida e Foucault como alguns de seus expoentes, a abordagem discursiva vê a linguagem, no aspecto conceitual de discurso, como primordial à construção da identidade. Segundo Pinto e Badan (2012), o conceito se atrela ao de linguagem, ao mesmo tempo que a existência social do sujeito, sua constituição e posicionamento tornam-se dependentes de um sistema linguístico.

$\mathrm{Na}$ busca por concepções menos fixas e unificadas, a característica flexível do discurso assemelha-se a características pós-modernas da identidade. A propósito, o novo paradigma caracterizado pelos estudos culturais vale-se dessa mesma ótica, distante, pois, de uma visão moderna, humanística e estável, mas mobilizada no e pelo discurso (HALL, 2006; WOODWARD, 2009), para percebê-la.

Sob uma condição móvel, em que há relativa liberdade humana sobre o discurso, a identidade configura-se de modo estável, podendo emergir de enunciações, performances, indexicalidades etc. (SILVA, 2012). Nessa acepção, serve à noção de contexto para exames da materialidade discursiva posta, lógicas de interlocução, circunstâncias e instâncias situadas em diferentes esferas da atividade humana, bem como para lógicas curriculares, culturais, enredadas por letramentos e agência (MACHADO; GIL, 2017; SLOAN, 2006). Além disso, pode-se ter como aporte teórico o discurso enquanto fabricante da identidade (MOITA LOPES, 1998), ou seja, como "processo" de significação manifestado em linguagem, e o discurso que leva à percepção de uma específica identidade, os chamados "discursos de identidade" (ALSUP, 2006; MOITA LOPES, 1998, 2003), concebidos como "produtos" da linguagem, por meio dos quais a identidade socialmente se constrói (NORTON; MCKINNEY, 2011).

Embora, nos estudos de LA observados, não apareçam de maneira tão estanque, na abordagem discursiva concentram-se dois vieses de análise da identidade: i) sóciohistórico (CORACINI, 2007; SIGNORINI, 1998) e ii) pragmático (MOITA LOPES; BASTOS, 2011; REES; PINTO, 2012; RAJAGOPALAN, 2001, 2003, 2006). Esses 
vieses geralmente são reconhecidos conforme a concepção de linguagem/língua adotada e/ou a afiliação teórica, à luz de esforços e caracterizações perpassando desde a Análise do Discurso (CORACINI, 2007; SIGNORINI, 1998) à Análise de Discurso Crítica (JASNIEVSKI, 2013; LEMKE, 2008; TORIZANI, 2005).

No viés sócio-histórico, abandona-se a noção de autoconsciência do sujeito e considera-se, de imediato, sua complexidade histórica e cultural. Se inexistem sujeitos sociais anteriores à linguagem, e se suas práticas sociais não são fixas, conforme Deters (2011), à condição de assujeitamento também se rende o dinamismo da identidade. Então, surge, como alternativa, a análise da identidade centrada em um viés caracterizado pelo processo contínuo vivido pela pessoa, abastecido pela formação social e, consequentemente, pelas formações ideológica e discursiva existentes no domínio social e no fluxo da história (DE NARDI, 2007).

Partindo da premissa de que não existe sujeito pre-existente à linguagem, e de que se desenvolve um senso de si apenas por meio da língua, a identidade é examinada sob a ordem do inconsciente e da determinação histórica e ideológica, movida pelo discurso. Assim, uma identidade conforma e é conformada por valores culturais que fazem com que as pessoas vejam o mundo - e constituam sua identidade - de uma forma e não de outra (CORACINI, 2007).

Pesquisas em LA que se balizam pelo viés sócio-histórico apresentam uma característica da identidade moldada no fluxo histórico dos acontecimentos, dos arquivos e memórias inter/discursivas, na dispersão dos enunciados, incluindo ideologias e historicidade. Para isso, as análises operam de forma diferenciada, caso se considerem as frentes teóricas utilizadas, as quais vão desde uma adesão lacaniana (CORACINI, 2000; ECKERT-HOFF, 2008) a uma compreensão bakhtiniana (COSTA, 2016; ELICHIRIGOITY, 2008; FALASCA, 2017). Nesse apego, aspectos éticos e estéticos do fenômeno identidade podem ser analisados (FALASCA, 2017), ao mesmo tempo que a aparição de identificações significantes seja um contingente para a identidade conferida àquela frente teórica.

No que tange ao viés pragmático, a identidade pode ser cotejada a partir de um sujeito que, para forjar ou despojar-se do próprio eu, no mero ato de comunicação, valese do contexto de interlocução para produzi-la, conforme sua intenção e desejo de assunção no momento de ocorrência. Sob vasta possibilidade de constituição, essa identidade é reivindicada de modo intencional, não neutro, dada a ocasião imediata de sua construção social durante a conversa (BOHN; TRINDADE, 2014).

A identidade, nesse viés, teria um aspecto consciente em termos de interpretação, porque, do ponto de vista de ocorrência real da interlocução, ao mesmo tempo que ela consiste em um posicionamento de A interpretado e conferido em sentido por $\mathrm{B}$, a reação linguística de $\mathrm{B}$ demanda uma posição que, por conseguinte, vai promover uma nova identidade em A. Para o aparecimento da identidade, levando-se em conta os atos de linguagem, tem de haver consciência e intencionalidade por parte do sujeito interpretante, que, por sua vez, também é responsável por apurar determinados sentidos existentes na relação social e, com isso, se posicionar, tornando cíclica cada identidade produzida.

Por esse caminho, a identidade aparece em virtude da interpretação do sentido veiculada pelo interlocutor durante atos comunicativos, ou mesmo quando esse 
interlocutor traz um parecer sobre dada relação social (SOARES, 2006). A priori, é o locutor que realiza a ação linguística no mundo, mas sua identidade só vem à tona quando esse dizer é palco político de interpretação. A construção identitária se dá, portanto, por intermédio do sentido instaurado na interlocução mediado pela linguagem, o qual só pode ser resgatado para o disparo de uma nova identidade, caso haja avaliações, demarcações e afirmações linguísticas promovidas pelos interagentes sobre si mesmos e sobre o/s outro/s. É esse movimento que ocorre quando há o contato da pessoa com uma nova língua, com novas culturas.

Do ponto de vista pragmático, a identidade, assim como o discurso, é entendida como performance (LEMKE, 2008; MASTRELLA-DE-ANDRADE, 2013; MISHLER, 2002). Isso significa dizer que ela emerge no fazer, nas práticas sociais e, de acordo com Lemke (2008), nas adaptações contextuais, na continuação de encontros e atuação nas relações sociais. Aqui não se firma, pois, uma ontologia que defina uma estrutura essencializada, depositada apenas na historicidade discursiva.

Assim como para Blommaert (2005), parece-nos consenso que, em primeiro momento, a identidade emergiria dos eventos interacionais de promulgação pragmática. Em segundo plano, após a ocorrência, seriam atribuídas, por parte do interpretante, categorias alojadas em um retrospecto avaliativo e estancado de caracterizações anteriormente reconhecidas e já, então, consensuais: charmoso, valente, chato etc. Isso ocorre porque o exercício de construção da identidade é relacional, dialético e não autoatribuído. Afinal, podemos ter atitudes de ousadia que façam com que o/s outro/s nos reconheça/m, nos leia/m ousados, sem ao menos termos essa consciência.

\subsection{ABORDAGEM COGNITIVA}

Alavancada pelo acolhimento das teorias psicológicas de Piaget, Wallon e Vygotsky aos processos de ensino/aprendizagem, também mostra-se produtiva a integração, em um primeiro momento, da ordem cognitiva/individual das experiências para, depois, no contexto de aquisição de línguas, segundo Norton e Mckinney (2011), expandir o caráter social da identidade misturado ao de linguagem em LA. Nessa configuração, o conceito passa a englobar o conhecimento socialmente produzido atrelado às dimensões pedagógica, psicológica e linguística da interação social (BARCELOS, 2013, 2015; MARCELO, 2009).

Um princípio relevante à abordagem, também postulado por teorias psicológicas mais recentes, é o de que a identidade se modifica conforme as mudanças no meio social em que a pessoa se insere. Isso se dá porque a cognição deriva de um processo mental e interacionista, em que a linguagem e o entorno social, incorporados a outros meios semióticos, assumem fundamental importância na constituição identitária.

Nesse modelo, de acordo com Deters (2011), existe uma relação dialética entre a mente humana, produto da linguagem, e o meio social. Assim, com a garantia da regulação de um indivíduo por outro/s, mutuamente se modificando sob uma progressão de desenvolvimentos, a assimilação de uma identidade é obtida no princípio de continuidade da experiência, integrando os fatores biológico, afetivo, social e intelectual. 
Os estudos que se enveredam por essa abordagem geralmente agregam, de uma perspectiva filo e ontogenética, diferentes fatores socioculturais, internos e externos ao indivíduo, como condicionantes da identidade. Se são os seres sociais que a produzem, logo, uma vez mediados coletivamente pela cultura, esses fatores inscritos na relação pedagógica colaboram para as devidas construções. Em geral, a abordagem cognitiva prevê os elementos psicológico e social e, ao mesmo tempo, histórico e desenvolvimental, para atribuir coerência à identidade.

Convalidando a adaptação biológica de organização do pensamento em Vygotsky (1998), parece-nos prevalecer na abordagem dois movimentos cíclicos de construção identitária: a) intrapessoal, em que a identidade é ponderada (in)conscientemente - pelo indivíduo - em conformidade com a avaliação e o julgamento balizados por outrem, e, ao mesmo tempo, b) interpessoal, resultante da ação e da influência (in)diretas de artefatos culturais e de outros meios de mediação conduzidos - pelo social - no próprio indivíduo. Ambos os caminhos valorizam o papel social do outro e geralmente se complementam, apostando na dimensão política existente na relação para a compreensão de si e dos outros.

A abordagem cognitiva correlaciona-se especialmente à teoria vygotskyana, na medida em que a atuação social das pessoas, que também valida suas identidades, depende de questões individuais e relacionais ressonantes e de fatores socioculturais e biológicos. Nesse caso, uma identidade nasce imbricada ao comportamento e às respostas das pessoas aos estímulos sociais e simbólicos estabelecidos em/por mediação. O contato com outras experiências e sujeitos desperta o potencial identitário no processo, sem apego denso às questões puramente de linguagem, mas, talvez pelo respaldo psicopedagógico de teorização aportada, exclusivamente endereçado à dimensão do ensino em geral.

Considerando que a teoria cognitiva estabelece a aprendizagem como resultante de um esquema de representações mentais, elementos linguísticos incorporados à relação contribuem para a construção de determinados conhecimentos, os quais, por sua vez, refletem a identidade, sem necessariamente referir-se especificamente a ela. No entorno social, uma identidade não surge isolada, mas associada dinamicamente a outros processos igualmente cognitivos, tais como motivação (OLIVEIRA, 2016), emoção (ARAGÃO; CAJAZEIRA, 2017; CAMARGO; BULGACOV, 2006; BARCELOS, 2017; ZEMBYLAS, 2005), subjetividade (SIGNORINI, 1998), entre outros.

Se a cadeia de fenômenos sociais ocorre - a exemplo do que temos com as representações e crenças (BARCELOS, 2013, 2015) - imbuída de linguagem, ela não pode funcionar apenas para integrar elementos sem uma análise criteriosa do que se interliga à identidade. Ao mesmo tempo que Barcelos (2013, p. 173) avança ao dizer que "crenças e emoções estão no cerne do que é nossa identidade", é preciso observar, segundo Hall (2009), que essas representações constroem a identidade, isto é, elas não correspondem à identidade.

Por se tratar de uma teoria suporte em boa parte dos estudos em LA, talvez o socioconstrutivismo condense mais fenômenos em seu repertório de análise do que o da própria identidade em si. Nesse caso, o esforço novamente está em se debruçar na apreensão de cada elemento que a integra. Em outros estudos, é apresentado um conceito livre para a identidade, sem muita preocupação com o acolhimento científico fundante, já que o argumento sociocultural, por si só, representa uma condição teorizante para o construto. 
O dilema de constituição da identidade previsto na abordagem cognitiva consiste em sua junção às categorias atividade e consciência (VYGOTSKY, 1998). Diante do que merece ser vivido sob as condições dadas (CIAMPA, 1987), a identidade torna-se um processo (in)consciente que depende da interpretação alheia criada. Do ponto de vista da ação social, sua emergência depende de um motivo, por sua vez encontrado no reflexo psíquico acompanhado de um tom emocional. Ou seja, as emoções, materializadas nas funções cerebrais, reguladas e condicionadas à experiência individual humana, representam papel ativo e desencadeador de ações mobilizadoras e anunciadoras da identidade (CAMARGO; BULGACOV, 2006; ARAGÃO; CAJAZEIRA, 2017).

\subsection{ABORDAGEM SITUADA}

Notabilizada por estudos antropológicos, a abordagem situada envolve o processo e a localização de fenômenos sociais, como a identidade, mediante o contexto em que práticas sociais se realizam. Em primeiro momento, uma noção relevante se pauta no princípio de inserção e participação de estranhos em uma comunidade específica (DETERS, 2011). Com os novos modos de vida, globais e tecnológicos, acoplando o dinamismo de 'ação' e 'relação' social, a complexidade geopolítica da identidade se avoluma, dinamizando a sistematização do conceito.

Lave e Wenger (1991) utilizam o conceito de aprendizagem situada como salutar à identidade no sentido de as pessoas filiarem-se socialmente umas às outras. $\mathrm{O}$ fato é que existe primordialmente um contexto - algumas vezes físico, mas sempre socialmente traduzível - no qual o indivíduo se situa e, a partir de suas práticas, constrói sentidos para si e para o entorno coletivo mediante mútua participação e engajamento. A partir disso, para além do contexto de aquisição de línguas, a identidade flui em localizações sociais, criando referências de filiação do indivíduo a grupos, comunidades, instituições etc. sob contextos de procedência para as devidas alusões.

Para Blommaert (2005), a noção de espaço é relevante à compreensão da identidade, porque pode oferecer, além de incursões empíricas importantes para seu desvelamento e desenvolvimento em determinada relação, como a de trabalho, por exemplo, suporte para que as relações significativas e eventos instaurados se ancorem a um senso de comunidade desenvolvido e de pertença. Tudo isso, afirma o autor, torna-se ingrediente para uma matriz semiótica em que se identificam membros e não-membros, por ocasião de variadas qualidades atributivas: caráter, estilo, preferências e modos específicos de comportamento.

\footnotetext{
O lugar define as pessoas, tanto a seus próprios olhos e aos olhos dos outros, e tais definições de pertença são mediadas através de indicialidades etnodialetais. E, obviamente, quando as pessoas ficam deslocadas, seus discursos se tornam desterritorializados - desconectados de seus espaços habituais e inseridos em novos regidos por novas regras (BLOMMAERT, 2005, p. 223).
}

Tomando a identidade pela lente semiótica (BLOMMAERT, 2005), evitamos reduzi-la à categoria estática, uma vez que começamos a pensá-la sob uma análise 
rigorosa de como pessoas se identificam com outras e como o fazem, utilizando-se dos meios que têm à sua disposição. Dessa maneira, é perceptível seu sistema policêntrico e, ao mesmo tempo, estratificado, já que se organiza por "tópico, situação, gênero, estilo, ocasião, finalidade, e assim por diante", e pode se desenvolver por meio dessas intersecções e hierarquias. Em suas palavras, "nem toda identidade terá a mesma gama ou extensão" (p. 210), pois dependerá do ambiente particular em que se vive.

O advento da globalização, assim como a compressão de espaço-tempo advinda dos avanços na área das tecnologias digitais e dos novos modos de vida social contemporânea (GIDDENS, 2002), produz contornos porosos para a identidade situada. Nesse caso, a identidade acolhe referências geográficas de várias comunidades, com diferentes visões de mundo e comportamento, causando o conflito e o trânsito propostos por diferenças interpeladas. Essa dimensão nos indica que o lugar não é exatamente físico, mas, sobretudo, contextual, por englobar significados resgatados por valores e costumes culturais presentes nas práticas organizadas em determinadas instâncias ou, ainda, fruídas por valores que o indivíduo leva consigo e que o fazem pertencer a dada cartografia. Assim sendo, sua identidade, diluída em aspectos situados, se condiciona ao pertencimento contextual e se materializa como lugar de fala.

Automaticamente, o dinamismo da identidade se inter-relaciona (in)diretamente com o contexto social que lhe é imanente (GEE, 2001) e em conformidade com o lócus da materialidade linguística enunciada. Engrenada a uma variedade de processos localizados na construção de sentidos, sejam esses vigorados pelo discurso ou pela experiência, a abordagem situada, além do senso de pertença, recebe apoio da posição social e posicionamento de sujeitos, bem como de processos de alteridade (CHARAUDEAU, 2009; COSTA, 2016).

As pessoas falam de um lugar e levam em conta suas profundas ligações particulares com esse ambiente, incluindo formas de linguagem/cultura ali presentes. Há uma atribuição qualitativa desse lugar social para o que dizem. As variedades linguísticas fazem movimento orgânico e enunciam lugares (sociais) ao serem usadas por pessoas que lhes fazem referência. Segundo Riley (2003), a identidade está codificada em nossa linguagem, organizada em repertórios lexicais, distribuída em nosso modo de falar (sentir e acreditar) e sobre como falam de nós, a partir de declarações (afirmações identitárias) que denotam afiliações.

Para efeito de análise, a diversidade linguística torna-se um campo de significados, inclusive identitário, porque nos conduz à compreensão de como as pessoas se situam e para que e quem elas falam. Logo, ao variarem os turnos discursivos, pode haver mudanças na fabricação dessas identidades (BLOMMAERT, 2005).

Especialmente no circuito da cultura, a identidade se constitui de forma heterogênea. Nas relações intersubjetivas, realizadas em contextos, ela se efetiva pelo contraste, algumas vezes imperceptível a interlocutores. Sendo assim, é estabelecida à medida que existem disputas e posicionamentos entre sujeitos, percepções, sentidos, avaliações e demarcações em relação àquilo que se mostra diferente. Como destaca Charaudeau (2009, p. 1, grifo do autor), 
É somente ao perceber o outro como diferente, que pode nascer, no sujeito, sua consciência identitária. A percepção da diferença do outro constitui de início a prova de sua própria identidade, que passa então a "ser o que não é o outro". A partir daí, a consciência de si mesmo existe na proporção da consciência que se tem da existência do outro. Quanto mais forte é a consciência do outro, mais fortemente se constrói a sua própria consciência identitária. É o que se chama de princípio de alteridade. Esta relação ao outro se institui através de trocas que fazem com que cada um dos parceiros se reconheça semelhante e diferente do outro.

Considerando que a identidade, assim como a linguagem, demanda posicionamentos sociais (WOODWARD, 2009) envolvendo produção de sentidos, ela se movimenta dinamicamente mediante episódios de des/re/construção (MACHADO; GIL, 2017), a depender do contexto e dos efeitos de significação surtidos em determinadas cenas enunciativas (SOUSA, 2006). Nesse caminho, participar ou não participar de uma 'comunidade' produz determinadas identidades, já que nos construímos a partir daquilo que também optamos por não participar.

Sob o princípio de posicionamento social, a identidade se torna emergente e se revela no outro. Nessa relação, suas imbricações permeiam os marcadores raça (BOHN; TRINDADE, 2014; FERREIRA, 2012, 2017) e gênero (MOITA LOPES, 2002), entre outras intersecções, que atravessam distintos arranjos de modalidade linguística, por sua vez configurados em aspectos verbal (oral e escrito) e/ou não-verbal (visual e semiótico). Pesquisas feministas em LA têm usado o posicionamento social para estudar a identidade, o qual, por sua vez, se funda pragmaticamente no uso da pessoa verbal, denotando assunção à causa política de enfrentamento (PINTO; BADAN, 2012).

Os 'marcadores identitários', como salientam Pinto e Badan (2012), se relacionam linguisticamente com o posicionamento e também com o senso de pertença, podendo se articular a indivíduos ou a grupos. Ao mesmo tempo que se tem uma identidade jovem, por exemplo, essa pode ser amparada por diversos entrecruzamentos, os quais podem ser lidos como categorizações. A categorização, aliás, é um movimento de demarcação individual, ainda que moderno, em conjunto com uma incisiva noção de representação geralmente obtida na coletividade.

Não obstante, a identidade possui como característica o componente de inclusão e de exclusão em comparação com aspectos que identificam ou diferenciam grupos e pessoas. Sob o senso de pertencimento, uma identidade docente é assumida porque a pessoa identificada se situa em determinada classe/grupo/camada social e, com isso, rejeita outros atributos materializados na diferença. Nesse mesmo exemplo, nota-se que, ao mesmo tempo que se afirma a identidade de professor, é possível também demarcar em linguagem posições tais, tendo em vista a diferença inerente ao outro (SILVA, 2009). Isso tudo só pode ser estabelecido por ocasião do trabalho potencial exercido pela linguagem, que também consiste em uma justificativa comumente utilizada por pesquisas em LA para subsidiar o estudo da identidade.

A identidade numa abordagem situada abriga ainda perspectivas micro/macro ao incorporar categorias culturais de pertencimento, as quais vão desde uma relação de nacionalidade (mais abrangente), como brasileiro, a uma relação de comportamento de grupo/comunidade mais restrito (específica), goiano, sertanejo, corajoso, entre outras. Embora ambas tenham o respaldo coletivo e contemplem perspectivas polarizadas, não deixam de se configurar como identidades individuais diante de uma noção coletivizada e cartografada. 
Para Blommaert (2005, p. 207), a identidade não é "uma propriedade ou uma categoria estável de indivíduos ou grupos, mas formas particulares de potencial semiótico, organizado em um repertório".

as pessoas não possuem uma identidade, mas as identidades são construídas em práticas que produzem, promulgam, ou performam identidade - identidade é identificação, um resultado de um trabalho semiótico condicionado socialmente (BLOMMAERT, 2005, p. 205).

Em interface com estudos interculturais, o construto reivindica ainda a relação de alteridade como base para discussão dos processos e práticas de ensino/aprendizagem de línguas (CORACINI, 2007; PICONI; MATEUS, 2011). Em alguns deles, a base do dialogismo bakhtiniano se manifesta pela condição dialética da linguagem no mundo social (COSTA, 2016; MAIOR; LUZ, 2019). Em outros, prevalece o senso de si numa elaboração mais lacaniana, conforme já ponderamos. Por essa razão, para análise da identidade há que se prever também a forma de conceber o outro (Bakhtin) ou o Outro (Lacan), ou seja, o papel da/s pessoa/s com quem nos relacionamos. As reservas aqui se valem de um eu dirigido a outro, ambos subsidiados pela linguagem.

\section{OS CAMINHOS DIACRÔNICO E SINCRÔNICO DA LINGUAGEM NA ANÁLISE DA IDENTIDADE}

São tentaculares as formas de se perscrutar o conceito identidade em LA. Em analogia à dicotomia saussuriana, dois caminhos - diacrônico e sincrônico - nos parecem promissores para se conceber suas noções singularizada e pluralizada. Por intermédio da diacronia, é possível observar a identificação de uma pessoa e toda sua historicidade sendo atravessada por momentos de construção identitária. Nesse caso, quando singularizada, temos uma identidade resultante das representações por que um indivíduo passa em sua trajetória, a partir de descartes ou adesões. Esse caminho é geralmente percorrido por estudos educacionais (CONNELLY; CLANDININ, 1999), sobre os quais se subentende o essencialismo da identidade mediante interpelação individual/coletiva, podendo modificar ou enrijecer-se com o tempo (DANIELEWICZ, 2001). A solidez identitária, a propósito, requer de pesquisas contornos metodológicos mais longitudinais, haja vista o fato de as pessoas mudarem com o tempo, sendo dificultoso compreender por que cada uma se tornou ou se constituiu de determinada forma ou de outra.

Embora resvale mais sobre uma ideia ortodoxa de identidade ou contemple uma noção mais estática de sujeito, se nos conduzirmos pelo caminho diacrônico singularizado, as análises de identidade (no singular) parecem mais promissoras no sentido de vasculhar a trajetória individual caracterizada por valores modificados no decorrer do tempo e do modo de vida de um sujeito, de maneira a consubstanciar a sua identidade, unificada. Com isso, teríamos um tom lacaniano de análise relacionado à percepção de si por intermédio da linguagem (DE NARDI, 2007; RAMBO, 2004). 
Pensar o viés diacrônico singular da identidade em estudos de LA significa discursivamente resvalar em aspectos dialógicos e sociais da linguagem e, numa linha cognitiva, combinar a identidade como produto das interações sociais e das experiências realizadas em linguagem pelo sujeito ao longo de sua vida. Dessa forma, um critério psicanalítico, caracterizado pelas experiências de vida que se confirmam diante do resultado daquilo que o sujeito "se tornou", se traduz em uma espécie de eu-produto dos acontecimentos ocorridos, servindo como base de constituição identitária para a proposta. Seria relevante a seguinte pergunta: como determinado sujeito se tornou assim?

A pergunta geralmente motiva condições em que se percebe a identidade como resultado dos fragmentos de crenças/representações, as quais se deslocam e modificam ao longo da trajetória de vida humana (BARCELOS, 2013, 2015; CORACINI, 2007; MAIOR; LUZ, 2019; SIGNORINI, 1998). Aqui, consideramos a unificação, porque, ainda que a identidade do indivíduo - por quais sejam os motivos - se movimente ao longo de sua vida e se modifique, ela resulta dos pontos de apego temporário das identificações que, por sua vez, pressupõem representações.

É também o caminho diacrônico singular que alguns estudos pioneiros sobre identidade em LA percorrem (BARCELOS, 2013, 2015, 2017) ao incluir outros elementos cognitivos intrincados ao fenômeno, já que todos se prestam a conceitos inseparáveis das ações e dos dizeres do sujeito. Para Barcelos (2013), Aragão e Cajazeira (2017) e Lemke (2008), a identidade é o resultado da imbricação de determinados valores construídos social e culturalmente, dentre os quais, crenças e emoções. Logo, sua base cognitiva se respalda por artefatos linguísticos e psicológicos bastante coerentes (BEIJAARD et al., 2004).

No caminho sincrônico pluralizado, a identidade se torna menos palpável, por conta das várias possibilidades que um sujeito tem de forjá-la no imediato da interlocução. Durante a ocorrência do ato de comunicação no mundo, em que as pessoas abdicam de ou afirmam certa identidade, não há a preocupação com os fatores tempo, história e circunstância ideológica de linguagem que a rondam, anteriores à interlocução. $\mathrm{O}$ efeito pragmático é preponderante para construir as identidades, no plural, de maneira posicional e estratégica (MOITA LOPES, 2001, 2003; RAJAGOPALAN, 2001).

Isso ocorre porque a sincronização parece inspirar mais valor à performance, conforme os sentidos linguísticos vão sendo veiculados, de modo a produzir discursivamente variadas identidades. Dessa perspectiva, o sujeito é intencional, consciente e suas identidades dependem das afirmações de sentido dos outros para emergir (RAJAGOPALAN, 1998). Ou seja, o que importa é o "aqui e agora" no ato da comunicação e o papel do interlocutor no uso da linguagem. Todas essas faces incorporadas no momento de ocorrência se apresentam como primordiais para que a identidade do locutor se forje. Podem aparecer várias ao mesmo tempo, a depender dos efeitos das interpretações construídas.

Para todas as abordagens descritas anteriormente, o viés sincrônico é uma possibilidade latente, porque se confirma o ideal de contexto enunciativo imediato de interação, o qual é composto de elementos extra/linguísticos, às vezes somados a outros processos, como de alteridade, de polidez etc., a prescrever quais identidades devem ser usufruídas, abandonadas e quais devem estar dispostas no momento da comunicação em que os sentidos das relações sociais são conferidos. 
Nessa perspectiva, a pessoa com quem eu falo constitui os propósitos de surgimento ou apagamento de determinada identidade. É esse interlocutor o responsável por balizar e moldar discursos constituidores de uma identidade provisória e pragmaticamente marcada. Caberia, aqui, a seguinte interrogação: por que e para que determinado sujeito se torna ou constitui suas identidades de determinada forma? Nesse caso, considerando a linguagem "impregnada da noção de poder e de efeitos", operando "identidades e possibilita[ndo] deslocamentos identitários" (PINTO; BADAN, 2012, p. 136), teríamos várias identidades constituidoras do eu, para as quais os atos de fala e as relações de poder certamente teriam validade em negociação, uma vez abastecidos de linguagem (MASTRELLA-DE-ANDRADE; NORTON, 2011; NORTON; MCKINNEY, 2011; RAJAGOPALAN, 2003). Contudo, insistimos, esses caminhos são bastante dispersos e dificultosos ao se analisar o conceito.

\section{A HIBRIDIZAÇÃO DE CONCEITOS E CARACTERIZAÇÕES}

Considerando que a construção social da identidade denota teores de inventividade humana, as abordagens apresentadas, em conjunto com os fios de definições que a alastram, ainda que incipientes, levando-se em conta a complexa rede de relações e configurações que toma o conceito, tornam-se bastante promissoras para se pensar como as pessoas, por intermédio de práticas sociais de linguagem, tais como o contexto de ensino/aprendizagem de línguas, negociam, constroem, reconstroem ou desconstroem identidades (CONCEIÇÃO, 2013; OLIVEIRA, 2017a, 2017b; PICONI; MATEUS, 2011; TICKS, 2008).

Ainda que não se mostre simplificada a articulação de como toda essa abrangência de caracterizações se efetiva nas relações sociais, porque também diz respeito à dinâmica relação de fenômenos intrincados a instâncias psicológicas e sociais, as taxonomias construídas em torno do conceito identidade apresentam farta configuração face à relação de envolvimento com outros objetos de análise. Poderíamos, a título de ilustração, combinar as abordagens discursiva e situada, aqui classificadas, agrupando-as ao pósestruturalismo a partir das noções: local, subjetividade e posições de sujeito, e vinculálas a uma linhagem mais "crítica" detida por alguns estudos, assim como também poderíamos, apoiados em Lemke (2008), destacar a mescla dos atributos cognitivos, discursivos e situados da/s identidade/s aqui explorados etc.

Diante de tantas possibilidades para o exame da identidade, uma reflexão pertinente nos salta aos olhos: a garantia de que não se trata de procedimentos de análise estanques. Assim como a identidade forjada por uma pessoa, o arranjo de caracterizações que aqui propomos, em vários níveis, não pode ser reduzido ao ato simplista de considerar a identidade de maneira isolada, tampouco apenas em conjunto, sem uma inteligibilidade aparente. Aqui estamos descrevendo possibilidades de interpretação do processo, a partir do que mostram estudos da área, sem desconsiderarmos o inevitável hibridismo que dá qualidade ao conceito.

Não obstante, é preciso, sim, perceber a partir de que lente experimentamos a noção de identidade (RAJAGOPALAN, 2006), isto é, a partir de quais caminhos, abordagens 
e/ou paradigmas faremos a opção de análise. Compreenderemos a identidade como fenômenos estáveis e fixos, a rigor moderno, ou pensaremos em sua volatilidade, adensada pela linguagem, considerando que, enquanto professores, podemos assumir, a depender dos contextos de atuação, identidades de filhos, pais, maridos, netos, dançarinos, pesquisadores etc.?

Em contextos globais e pós-modernos, há o respaldo paradigmático para as identidades cambiantes, fluidas, contraditórias, híbridas (HALL, 2006), atravessadas por novos modos de vida (GIDDENS, 2002). Se o presente século se incumbe de ideais inatingíveis para elas, que passam a ser moldadas pelas diferentes formas como representamos o mundo e como somos nele representados (MOSCOVICI, 2013), realmente torna-se dificultoso assimilá-las, caso continuemos apegados a essencialismos pautados por um matiz identitário definido. Muito mais do que uma questão de lente, a problemática esbarra em aspectos de ordem paradigmática: de como percebemos a afirmação ou mesmo a negação de certas identidades.

Toda a complexidade posta até aqui confirma o fato de que a sistematização do conceito de identidade em estudos de LA envolve paradigmas sociais. O dilema perpassa desde concepções monolíticas, precisas e cristalizadas da identidade a noções mais transitórias, sem o controle de "blocos fixos de definições pré-estabelecidas" (PINTO; BADAN, 2012, p. 50). Temos muito volume de elementos agrupados à identidade quando se observam questões de língua (REES; PINTO, 2012), de modo que estancá-los tornase muitas vezes improdutivo.

À guisa de sistematização, porque entendemos todo esse processo e procedimentos como abundantes para a análise da identidade, propomos um quadro de possibilidades teórico-metodológicas conceituais a ser aproveitado em estudos em LA:

\begin{tabular}{|l|l|l|}
\hline DISCURSIVO & COGNITIVO & SITUADO \\
\hline Identidades & Identidade & Identidade/s \\
\hline Discurso & Linguagem/Cognição & Língua/Cultura \\
\hline Contexto Enunciativo & Contexto Interacional & Contexto Cultural \\
\hline A partir de Bakhtin & A partir de Vygotsky & A partir de Hall \\
\hline Práticas Discursivas & Entorno sociocultural & Vivência glocal \\
\hline $\begin{array}{l}\text { Interdisciplinaridade da LA } \\
\text { com a Sociologia, Filosofia e } \\
\text { o pensamento crítico }\end{array}$ & $\begin{array}{l}\text { Interdisciplinaridade da LA } \\
\text { com a Educação/Psicologia }\end{array}$ & $\begin{array}{l}\text { Interdisciplinaridade da LA } \\
\text { com a Antropologia/Estudos } \\
\text { Culturais }\end{array}$ \\
\hline $\begin{array}{l}\text { Sujeito discursivo } \\
\text { (sócio-histórico ou } \\
\text { intencional) }\end{array}$ & Sujeito sociocognitivo & Sujeito glocal \\
\hline Dialogismo & Afetividade & Alteridade e pertencimento \\
\hline
\end{tabular}

\section{Quadro 1 - Domínios preponderantes da identidade em estudos de LA}

Fonte: Frank e Conceição (2021). 
Como destacamos, não há necessidade de se construir uma dicotomia resistente aos domínios apresentados; tampouco compartimentalizar o fluir das abordagens e caminhos que permeiam a identidade. Pelo contrário, diante de uma postura híbrida, pós-moderna, parece produtivo não essencializar ou separar as vertentes apresentadas, e é o que os pesquisadores geralmente fazem, uma vez estabelecido seu escopo de pesquisa (DE NARDI; GIL, 2015).

Contudo, para fins de sistematização científica sobre o conceito de identidade resenhado na LA, torna-se relevante a predominância de certas características, mesmo diante das abstrações oferecidas, uma vez que fazem ressonâncias às teorias linguísticas e linguístico-aplicadas com suas interdisciplinaridades captadas em busca de como o objeto pode ser percebido teórica e metodologicamente. Essa base estabelecida talvez seja fundamental ao entendimento pormenorizado e à observação de como a complexidade que abrange o tema identidade pode ser esmiuçada, se consideradas as diferentes discussões científicas, uma vez que nosso propósito maior foi o de conferir inteligibilidade e relevância às interpretações teórico-metodológicas futuras.

\section{CONSIDERAÇÕES FINAIS}

Embora haja uma exploração intensa do conceito de identidade na LA, atravessada por apresentação de diversos rigores e métodos científicos, conforme indicamos no início deste artigo, o construto ainda merece detalhamento diante de sua abundância teórica e metodológica caracterizada pelo/no aspecto social. Isso é salutar porque há um consenso sobre as contingências por intermédio das quais é possível reivindicar a identidade sociais, políticas, históricas, econômicas, culturais etc. Por isso, compreendemos que buscar sistematização para sua análise em nossa área corrobora reflexões acerca das inquietações concretas propagadas pela influência que o tema exerce nos espaços intersubjetivos de ensino/aprendizagem de línguas. Nesse sentido, a linguagem constituise como um rico componente, na tentativa de estabelecermos alguns percursos para melhor compreender a identidade (TORIZANI, 2005).

As conexões para as quais as taxonomias aqui apresentadas apontam nos oferecem amplitude para trabalhar com a identidade em contextos sociais envolvendo linguagem. Não queremos - ao mesmo tempo que não podemos evitar - o paradigma moderno em choque com o pós-moderno, balizando as referidas categorizações (RAJAGOPALAN, 2006). Uma vez que as abordagens não estabelecem limites absolutos entre si, assumimos suas múltiplas possibilidades como relevantes, a depender do objetivo que permeia cada estudo de identidade a se desenvolver, no sentido de orientar como se possa conduzi-lo.

Nosso esforço foi o de tentar mostrar que existem particularidades e diferenciações notáveis acerca do conceito oferecidas por diversos estudos aqui mencionados, as quais podem auxiliar na orientação de futuras pesquisas sobre identidade. Ao apresentarmos características particionadas, não esgotamos a possibilidade de agrupá-las. Precisamos, isso sim, nos guiar pelo método de pesquisa perseguido, o qual deve se responsabilizar pela delimitação de abrangências, para que haja maior aprofundamento científico em análise. 
ALSUP, J. Teacher identity discourses: negotiating personal and professional spaces. Mahwah, NJ: Lawrence Erlbaum Associates, 2006.

ARAGÃO, R. C.; CAJAZEIRA, R. Emoções, crenças e identidades na formação de professores de inglês. Caminhos em Linguística Aplicada, v. 16, p. 109-133, 2017.

BARCARO, C. F. A menina que falava inglês: a construção identitária de uma professora de inglês sob as lentes da pesquisa com base em narrativas. 2012. Dissertação (Mestrado em Estudos da Linguagem) Universidade Estadual de Londrina, Paraná, 2012.

BARCELOS, A. M. F. Desvelando a relação entre crenças sobre ensino e aprendizagem de línguas, emoções e identidades. In: GERHARDT, A. F. L. M.; AMORIN, M. A.; CARVALHO, A. M. (Org.). Linguística Aplicada e ensino: língua e literatura. Campinas: Pontes, 2013. p. 153-186.

BARCELOS, A. M. F. Unveiling the relationship between language learning beliefs, emotions, and identities. Studies in Second Langauge Learning and Teaching, v. 5, p. 301-325, 2015.

BARCELOS, A. M. F. Identities as emotioning and believing. In: BARKHUIZEN, G. (Org.). Reflections on Language Teacher Identity Research. New York: Routledge, 2017. p. 145-150.

BEIJAARD, D.; MEIJER, P. C.; VERLOOP, N. Reconsidering research on teachers' professional identity. Teaching and Teacher Education, 20, p. 107-128, 2004.

BLOMMAERT, J. Discourse: a critical introduction. New York: Cambridge University Press, 2005.

BOHN, H.; TRINDADE, C. As palavras 'cor' e 'raça' (não) ecoam na linguagem dos documentos governamentais sobre educação. Identidade! v.19, n. 1, p. 23-31, 2014.

BUCHOLTZ, M.; HALL, K. Identity and interaction: a sociocultural linguistic approach. Discourse Studies, vol. 7, p. 585-614, 2005.

CAMARGO, D.; BULGACOV, Y. L. M. Introdução. In: CAMARGO, D.; BULGACOV, Y. L. M. (Org.). Identidade e emoção. Curitiba: Travessa dos Editores, 2006. p. 11-22.

CÂNDIDO JÚNIOR, A.; CONCEIÇÃO, M. P.; FRANK, H. Aprendizagem de língua estrangeira na terceira idade: marcas identitárias e representações sociais acerca do idoso. In: TAVARES, C. N. V.; MENEZES, S. F. (Org.). Envelhecimento e modos de ensino-aprendizagem. Uberlândia: EDUFU, 2020. p. 64-83.

CAPPARELli, C. P. A.; FRANK, H.; MEOTTI, J. P. ; PINHEIRO NETO, J. E. Problematizando identidades de gênero e sexualidade a partir de narrativas de uma professora de línguas. Glauks, v. 18, p. 242-259, 2018.

CHARAUDEAU, P. Identidade social e identidade discursiva, o fundamento da competência comunicacional. In: PIETROLUONGO, M. (Org.). O trabalho da tradução. Rio de Janeiro: Contra Capa, 2009. p. 309-326.

CIAMPA, A. C. Políticas de identidade e identidades políticas. In: DUNKER; C. I. L.; PASSOS, M. C. (Orgs.). Uma psicologia que se interroga: ensaios. São Paulo: Edicon, 2002. p. 120-135.

CIAMPA, A. C. A estória do Severino e a história da Severina: um ensaio de psicologia social. São Paulo: Brasiliense, 1987.

CONCEIÇÃO, M. P. Teacher's narratives: revealing experiences and conflicting identities. In: FIGUEIREDO, C. J.; MASTRELLA-DE-ANDRADE, M. R. (Org.). Ensino de línguas na contemporaneidade: práticas de construção de identidades. Campinas: Pontes, 2013. p. 305-317.

CONCEIÇÃO, M. P. O si mesmo como um outro: identidades em narrativas visuais de aprendizes de português como segunda língua. Trabalhos em Linguística Aplicada, v. 59, p. 1339-1372, 2020.

CONCEIÇÃO, M. P.; ANDRADE, F. S. B. Linguagens, vozes e discursos: identidades de uma trabalhadora doméstica. Cadernos de Linguagem e Sociedade, v. 21, p. 292-312, 2020.

CONCEIÇÃO, M. P.; FLORINDO, G. Identidades, investimento e comunidades imaginadas de aprendizes de Braille. The Especialist, v. 41, p. 1-16, 2020.

CONCEIÇÃO, M. P.; SILVEIRA, C. G.; NASCIMENTO, J. F. Representações e marcas identitárias em narrativas de professores sobre suas experiências com o uso de tecnologias na pós-graduação. In:

FINARDI, K.; SCHERRE, M.; VIDON, L. (Org.). Língua, discurso e políticas: desafios contemporâneos. Campinas: Pontes, 2019. p. 55-78. 
CONNELLY, F. M.; CLANDININ, D. J. Shaping a professional identity: stories of educational practice. New York: Teachers College Press, 1999.

CORACINI, M. J. Subjetividade e Identidade do professor de Português. Trabalhos em Lingüistica Aplicada, n. 36, p. 147-158, 2000.

CORACINI, M. J. A celebração do outro: arquivo, memória e identidade. Mercado de Letras: São Paulo, 2007.

COSTA, M. A. L. M. A constituição da identidade docente na escrita de memoriais em turmas de magistério. 136 f. Dissertação (Mestrado em Estudos da Linguagem) - Universidade Federal do Rio Grande do Norte, Natal, 2016.

CUNHA, N. M.; OLIVEIRA, H. F. Crise de identidade: questões ideológico-conceituais de gênero. In: VIEIRA, M. S.; BONAFIM, A. (Org.). Problematizações e debates em língua e literatura. Curitiba: CRV, 2019. p. 79-86.

DANIELEWICZ, J. Teaching selves: identity, pedagogy and teacher education. Albany, NY: State University of New York Press, 2001.

DETERS, P. Identity, agency and the acquisition of professional language and culture. London: Continuum, 2011.

DE NARDI, F. S. Um olhar discursivo sobre língua, cultura e identidade: reflexões sobre o livro didático para o ensino de espanhol como língua estrangeira. $190 \mathrm{f}$. Tese (Doutorado em Teorias do Texto e do Discurso) - Universidade Federal do Rio Grande do Sul, Porto Alegre, 2007.

DE NARDI, D. A. C.; GIL, G. How do I see myself? What do I want to become? A study on English as an additional language teachers' identity reconstruction. Trabalhos em Linguistica Aplicada, v. 54, n. 1, p. 137-160, 2015.

DINIZ-PEREIRA, J. E. Lentes teóricas para o estudo da construção da identidade docente. Educação em Perspectiva, v. 7, n. 1, p. 9-34, 2016.

ECKERT-HOFF, B. M. Escritura de si e identidade: o sujeito-professor em formação: Campinas: Mercado de Letras / FAPESP, 2008.

ELICHIRIGOITY, M. T. A formação do sentido e da identidade na visão bakhtiniana. Cadernos de Letras da UFF, n. 34, p. 181-206, 2008.

ERIKSON, E. H. Identidade, juventude e crise. Rio de Janeiro: Zahar editores, 1972.

FALASCA, P. 'Eu disse tudo isso em alemão, mas em português penso totalmente diferente': identidade e argumentação na sala de aula de língua estrangeira. f. Tese (Doutorado em Linguística e Língua Portuguesa) - Faculdade de Ciências e Letras, Universidade Estadual de São Paulo, Araraquara, 2017.

FERREIRA, A. J. (Org.) Identidades sociais de raça, etnia, gênero e sexualidade: práticas pedagógicas em sala de aula de línguas e formação de professores/as. Campinas: Pontes, 2012.

FERREIRA, A. J. Identidades sociais de raça em estudos da linguagem: com atividades reflexivas. Ponta Grossa: Editora Estúdio Texto, 2017.

FIRTH, A.; WAGNER, J. Second/Foreign language learning as a social accomplishment: elaborations on a reconceptualized SLA. The Modern Language Journal, 91, p. 800-819, 2007.

GEE, J. P. Identity as an analytic lens for research in education. Review of research in education, v. 25, p. 99-125, 2001.

GIDDENS, A. Modernidade e identidade. Trad. Plínio Dentzien. Rio de Janeiro: Zahar, 2002.

HALL, S. Da diáspora: identidades e mediações culturais. In: SOVIK, L. (Org.). Trad. Adelaine La Guardia Resende et al. Belo Horizonte: Ed. UFMG, 2003.

HALL, S. A identidade cultural na pós-modernidade. Trad. Tomaz Tadeu da Silva; Guacira Lopes Louro. 7. ed. Rio de Janeiro: DP\&A, 2006.

HALL, S. Quem precisa da identidade? In: SILVA, T. T.; HALL, S.; WOODWARD, K. (Org.). Identidade e diferença: a perspectiva dos estudos culturais. 9. ed. São Paulo: Vozes, 2009. p. 103-133.

JASNIEVSKI, C. C. Insatisfação e mudanças: identidades sobre o real e o ideal nas bases de conhecimento do professor. 2013. Dissertação (Mestrado em Estudos da Linguagem) - Universidade Estadual de Londrina, Paraná, 2013.

KLEIMAN, A. B. A construção de identidades em sala de aula: um enfoque interacional. In: SIGNORINI, I. (Org.). Lingua(gem) e identidade: elementos para uma discussão no campo aplicado. Campinas: Mercado de Letras, 1998. p. 267-302. 
LASKY, S. A sociocultural approach to understanding teacher identity, agency and professional vulnerability in a context of secondary school reform. Teaching and Teacher Education, v. 21, p. 899916, 2005

LAVE, J.; WENGER, E. Situated learning: legitimate peripheral participation. Cambridge: Cambridge University Press, 1991.

LEMKE, J. L. Identity, development, and desire In: CALDAS-COULTHARD, C. R.; LEDEMA, R. (Org.). Identity trouble: critical discourse and contested identities. London: Palgrave, 2008. p. 17-42.

LIBERALI, F. C. A constituição da identidade do professor de inglês na avaliação de sua aula. Revista Brasileira de Lingüística Aplicada, v. 4, p. 45-56, 2004.

MACHADO, A. S.; MASTRELLA-DE-ANDRADE, M. R.; OLIVEIRA, H. F. A identidade do aprendiz de línguas autodidata em debate. Cenários: Revista de Estudos da Linguagem, v. 13, n. 1, p. 98-117, 2016.

MAIOR, R. C. S.; LUZ, L. S. F. Identidades docentes e a ética discursiva nas interações sugeridas nas consígnias de abertura no contexto de educação a distância. Calidoscópio, v. 17, n. 2, p. 395-413, 2019.

MACHADO, F. R.; GIL, G. The processes of construction, deconstruction and reconstruction of an IFSC English language teacher's professional identity. DELTA, v. 33, n. 2, p. 383-411, 2017.

MARCELO, C. Identidade docente: constantes e desafios. Formação docente: revista brasileira de pesquisa sobre formação de professores, v. 1, n. 1, p. 109-131, 2009.

MASTRELLA-DE-ANDRADE, M. R. Pensando identidades em contextos de ensino-aprendizagem de línguas: uma discussão teórica introdutória. In: FIGUEREDO, C. J.; MASTRELA-DE-ANDRADE.

(Org.). Ensino de línguas na contemporaneidade: práticas de construção de identidades. Campinas, SP: Pontes, 2013. p. 61-88.

MASTRELLA-DE-ANDRADE.; NORTON, B. Querer é poder? Motivação, identidade e aprendizagem de língua estrangeira. In: MASTRELLA-DE-ANDRADE, M. R. (Org.). Afetividade e emoções no ensino/aprendizagem de línguas: múltiplos olhares. Campinas: Pontes Editores, 2011. p. 89-114.

MEAD, G. H. Mind, self \& society: from the standpoint of a social behaviorist. Chicago: The University of Chicago Press, 1992.

MISHLER, E. G. Narrativa e identidade: a mão dupla do tempo. In: MOITA LOPES, L. P.; BASTOS, L. C. (Org.). Identidades: recortes multi e interdisciplinares. Campinas, São Paulo: Mercado de Letras, 2002. p. 97-119.

MOITA LOPES, L. P. Discursos de identidade em sala de aula de leitura de L1: a construção da diferença. In: SIGNORINI, I. (Org.) Língua(gem) e identidade: elementos para uma discussão no campo aplicado. São Paulo: Mercado de Letras, 1998. p. 303-332.

MOITA LOPES, L. P. Práticas narrativas como espaço de construção das identidades sociais: uma abordagem socioconstrucionista. In: RIBEIRO, B. T.; LIMA, C. C.; DANTAS, M. T. L. (Org.). Narrativa, identidade e clínica. Rio de Janeiro: IPUB/CUCA, 2001. p. 55-71.

MOITA LOPES, L. P. Identidades fragmentadas: a construção discursiva de raça, gênero e sexualidade em sala de aula. Campinas, SP: Mercado das Letras, 2002.

MOITA LOPES, L. P. Socioconstrucionismo: discurso e identidades sociais. In: MOITA LOPES, L. P. (Org.). Discursos de identidades: discurso como espaço de construção de gênero, sexualidade, raça, idade e profissão na escola e na família. Campinas, SP: Mercado de Letras, 2003. p. 13-38.

MOITA LOPES, L. P.; BASTOS, L. C. Introdução: entre saberes interdisciplinares e práticas sociais: o estudo da identidade em abordagens contemporâneas. In: BASTOS, L. C.; MOITA LOPES, L. P. (Org.). Estudos da identidade: entre saberes e práticas. Rio de Janeiro: Garamond, 2011. p. 13-31.

MOSCOVICI, S. Representações sociais: investigações em Psicologia Social. Petrópolis: Vozes, 2013. NORTON, B. Language, identity and the ownership of English. TESOL Quarterly, v. 31, n. 3, p. 409$429,1997$.

NORTON, B. Identity and language learning: back to the future. TESOL Quartely, 50 (2), p. 475-479, 2016.

NORTON, B.; MCKINNEY, C. An identity approach to Second Language Acquisition. In: ATKINSON, D. Alternative Approaches to Second Language Acquisition. New York: Routledge, 2011. p. 73-94.

OLIVEIRA, B. M. Crenças, motivações e identidades de alunos de língua inglesa de uma escola particular. 137 f. Dissertação (Mestrado em Letras) - Universidade Federal de Viçosa, Viçosa, 2016. 
OLIVEIRA, H. F. A bagagem do PIBID para a formação inicial docente e para a construção da identidade profissional. Trabalhos em Linguística Aplicada, v. 56, p. 913-934, 2017 a.

OLIVEIRA, H. F. Tiranias da identidade do professor de LE: crenças, emoções e ações por meio da linguagem. Letras Escreve, v. 6, p. 13-38, 2017 b.

OLIVEIRA, H. F. Discurso e identidade/s: diálogos e interfaces nos processos de ensino, aprendizagem e formação docente. In: HOLANDA, J. A.; CASELLA, C. A. O. (Org.). Linguagens, identidades e ensino: diálogos e interfaces. Anápolis: UEG, 2018. p. 13-28.

PAVLENKO, A.; BLACKLEDGE, A. Negotiation of identities in multilingual contexts. Tonawanda, NY: UTP, 2004.

PAVLENKO, A.; NORTON, B. Imagined communities, identity, and English language teaching. In: CUMMINS, J.; DAVISON, C. (Org.). International handbook of English language teaching. New York: Springer, 2007. p. 669-680.

PICONI, L. B.; MATEUS, E. F. Ressignificações de identidades de professores: uma análise do encontro com o outro. In REIS, S.; VAN VEEN, K.; GIMENEZ, T. (Org.). Identidades de professores de línguas. Londrina: EDUEL, 2011. p. 271-294.

PIMENTA, S. G. Formação de professores: identidade e saberes da docência. In: PIMENTA, S. G. (Org). Saberes pedagógicos e atividade docente. São Paulo, Cortez, 2012. p. 15-38.

PINTO, J. P.; BADAN, S. C. Feminismo e as identidades no cerne dos princípios de pesquisa. Calidoscópio, v. 10, p. 133-139, 2012.

RAJAGOPALAN, K. O conceito de identidade em lingüística: é chegada a hora de uma reconsideração radical? In: SIGNORINI, I. (Org.). Lingua(gem) e identidade: elementos para uma discussão no campo aplicado. Campinas, SP: Mercado de Letras, 1998. p. 21-45.

RAJAGOPALAN, K. ELT Classroom as an arena for identity clashes. In: GRIGOLETTO, M.; CARMAGNANI, A. M. Inglês como língua estrangeira: identidade, práticas e textualidade. São Paulo: Humanitas, 2001. p. 70-90.

RAJAGOPALAN, K. Por uma Linguística Crítica: linguagem, identidade e a questão ética. São Paulo: Parábola Editorial, 2003.

RAJAGOPALAN, K. Pós-modernidade e a política de identidade. In: RAJAGOPALAN, K.; FERREIRA, D. M. M. (Org.). Políticas em linguagem: perspectivas identitárias. São Paulo: Editora Mackenzie, 2006. p. 63-82.

RAMBO, H. H. The language and culture of identity: crafting a new self in a second language. Kent: Kent State University, 2004.

REES, D. K.; PINTO, J. P. Entrelugares e identidades monolíticas: leituras múltiplas de Anzaldúa em sala de aula. Cadernos de Linguagem e Sociedade, v. 13, p. 30-55, 2012.

REIS, S.; VAN VEEN, K.; GIMENEZ, T. (Org.). Identidades de professores de linguas. Londrina: EDUEL, 2011.

RILEY, P. Self-access as acces to 'self': cultural variation in the notions of self and personhood. In PALFREYMAN, D.; SMITH, R. (Ed.). Learner autonomy across cultures: language education perspectives. New York: Palgrave, 2003. p. 92-109.

SIGNORINI, I. Des(construindo) bordas e fronteiras: letramento e identidade social. In: SIGNORIN, I. (Org.). Lingua(gem) e identidade: elementos para uma discussão no campo aplicado. Campinas: Mercado de Letras, 1998. p. 139-171.

SILVA, L. M. A língua constitui o professor: identidades (conflitantes) de professores de línguas estrangeiras. 2012. 118 f. Dissertação (Mestrado em Letras) - Universidade Católica de Pelotas, Rio Grande do Sul, 2012.

SILVA, M; GREGGIO, S.; LUCENA, C. A.; DENARDI, D. A. C.; GIL, G. Unveiling teachers' identities. Signum: estudos de linguagem, v. 10, p. 199-222, 2007.

SILVA, T. T. A produção social da identidade e da diferença. In: SILVA, T. T.; HALL, S.; WOODWARD, K. (Org.). Identidade e diferença: a perspectiva dos estudos culturais. 9 ed. São Paulo: Vozes, 2009. p. 73-102.

SLOAN, K. Teacher identity and agency in school worlds: beyond the allgood/all-bad discourse on accountability-explicit curriculum policies. Curriculum Inquiry, 36 (2), p.119-152, 2006. 
SOARES, M. F. Compondo identidades: construindo diários na aula de língua inglesa. 2006. Tese (Doutorado em Linguística Aplicada e Estudos da Linguagem) - Pontifícia Universidade Católica de São Paulo, São Paulo, 2006.

SOUSA, R. M. R. Q. Professores de inglês da escola pública: investigações sobre suas identidades numa rede de conflitos. 2006. Dissertação (Mestrado em Letras) - Universidade de São Paulo, São Paulo, 2006. TELLES, J. A. Reflexão e identidade profissional do professor de LE: que histórias contam os futuros professores? Revista Brasileira de Lingüistica Aplicada, Belo Horizonte: UFMG, v. 4, n. 2, p. 57-83, 2004.

TICKS, L. K. (Re)construção de concepções, práticas pedagógicas e identidades por de professoras de inglês pré e em serviço. 2008. 328 f. Tese (Doutorado em Letras) - Universidade Federal de Santa Maria, Rio Grande do Sul, 2008.

TORIZANI, J. E. Análise crítica da identidade do professor de língua portuguesa da rede municipal de Jaraguá do Sul. 2005. Dissertação (Mestrado em Ciências da Linguagem) - Universidade do Sul de Santa Catarina, Tubarão, 2005.

UTIM, M. A.; FRANK, H. Construção identitária no contexto de sala de aula: problematizando narrativas de um garoto trans. In: VICENTE, R. B.; DEFENDI, C. L. (Org.). Estudos de linguagem em perspectiva: caminhos da interculturalidade. Porto de Galinhas: UFRPE, 2020. p. 3898-3903.

VARGHESE, M.; MORGAN, B.; JOHNSTON, B.; JOHNSON, K. A. Theorizing language teacher identity: three perspectives and beyond. Journal of language, identity, and education, vol. 4, p. 21-44, 2005.

VYGOTSKY, L. S. A formação social da mente: o desenvolvimento dos processos psicológicos superiores. São Paulo: Martins Fontes, 1998.

WOODWARD, K. Identidade e diferença: uma introdução teórica e conceitual. In: SILVA, T. T. da. (Org.). Identidade e diferença: a perspectiva dos estudos culturais.Petrópolis: Vozes, 2009. p. 7-72.

ZEMBYLAS, M. Discursive practices, genealogies, and emotional rules: A poststructuralist view on emotion and identity in teaching. Teaching and Teacher Education, n. 21, p. 935-948, 2005.

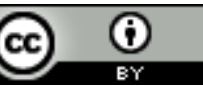

Este texto está licenciado com uma Licença Creative Commons Atribuição 4.0 Internacional. 